\title{
ADVANCES IN GRDDS: RAFT FORMING SYSTEM A REVIEW
}

\author{
Bhavsar Dhaval Niranjanbhai*, Varde Neha Mahendrakumar, C. Sini Surendran, Shah Viral H, Upadhyay UM \\ Dept. of pharmaceutics, Sigma Institute of Pharmacy, Bakrol, Vadodara(Gujarat), India \\ *Corresponding Author's Ph: +91-9725512814, Email id: dhaval bhavsar18@yahoo.com
}

Received 06 June 2012; Review Completed 26 Aug 2012; Accepted 26 Aug 2012, Available online 15 Sep 2012

\begin{abstract}
:
In recent years several advancements has been made in research and development of Gastro retentive drug delivery system to overcome the drawback of non-site specificity when drug administered orally. In order to understand various physiological difficulties to achieve gastric retention, we have summarized important factors controlling gastric retention time. We have reviewed various gastro retentive approaches designed and developed until now i.e. floating drug dosage systems (FDDS), swelling or expanding systems, mucoadhesive systems, high density system, Raft forming system, magnetic systems. Among these systems, the review summarizes the special focus on raft forming approach which comes under floating drug delivery system. Raft system incorporates alginate gels which have carbonate components react with gastric acid causes bubbles and this enables floating. Finally, Evaluation, advantages, disadvantages, future potential and marketed preparation of raft forming approach in gastro retentive drug delivery systems were covered.

Key words-Advances in GRDDS, Raft forming system, alginic acid, gaviscon,
\end{abstract}

\section{INTRODUCTION:}

Conventional oral delivery is widely used in pharmaceutical field to treat diseases. However, conventional delivery had many drawbacks and major drawback is non-site specificity. Some drugs are absorbed at specific site only. They require release at specific site or a release such that maximum amount of drug reaches to the specific site. Pharmaceutical field is now focusing towards such drugs which require site specificity. Gastroretentive delivery is one of the site specific deliveries for the delivery of drugs either at stomach or at intestine. It is obtained by retaining dosage form into stomach and drug is being released at controlled manner to specific site either in stomach, duodenum and intestine.

\section{MERITS OF GRDDS ${ }^{2}$}

$\checkmark \quad$ Delivery of drugs with narrow absorption window in the small intestine region.

$\checkmark \quad$ Longer residence time in the stomach could be advantageous for local action in the upper part of the small intestine, for example treatment of peptic ulcer disease.

$\checkmark \quad$ Improved bio-availability is expected for drugs that are absorbed readily upon release in the GI tract such as cyclosporine, ciprofloxacin, ranitidine, amoxycillin, captopril, etc.

$\checkmark \quad$ Patient compliance by making a once a day therapy.

$\checkmark \quad$ Improved therapeutic efficacy

\section{DRUGS WHICH REQUIRE GASTRIC RETENTION ${ }^{3}$}

1) Drugs acting locally in the stomach E.g. Antacids and drugs for H. Pylori viz., Misoprostol

2) Drugs that are primarily absorbed in the stomach E.g. Amoxycillin

3) Drugs those are poorly soluble at alkaline $\mathrm{pH}$

E.g. Furosemide, Diazepam, Verapamil, etc.
4) Drugs with a narrow window of absorption E.g. Cyclosporin, Methotrexate, Levodopa, etc.

5) Drugs which are absorbed rapidly from the GI tract. E.g. Metonidazole, tetracycline.

6) Drugs that degrade in the colon. E.g. Ranitidine, Metformin $\mathrm{HCl}$.

\section{LIMITATIONS OF THE TECHNIQUES OF GASTRORETENTION ${ }^{2,3}$}

More predictable and reproducible floating properties should be achieved in all the extreme gastric conditions.

1. The floating systems in patients with achlorhydria can be questionable in case of swellable systems, faster swelling properties are required and complete swelling of the system should be achieved well before the gastric emptying time.

2. Bioadhesion in the acidic environment and high turnover of mucus may raise questions about the effectiveness of this technique. Similarly retention of high density systems in the antrum part under the migrating waves of the stomach is questionable.

3. Not suitable for drugs that may cause gastric lesions e.g. Non- steroidal anti-inflammatory drugs. Drugs that are unstable in the strong acidic environment, these systems do not offer significant advantages over the conventional dosage forms for drugs that are absorbed throughout the gastrointestinal tract.

4. The mucus on the walls of the stomach is in a state of constant renewal, resulting in unpredictable adherence.

5. In all the above systems the physical integrity of the system is very important and primary requirement for the success of these systems. 
Table1: comparison of conventional drug delivery system and GRDDS ${ }^{1}$

\begin{tabular}{|l|l|}
\hline CONVENTIONAL DRUG DELIVERY SYSTEM & GASTRORETENTIVE DRUG DELIVERY SYSTEM \\
\hline High risk of toxicity & Very low risk of toxicity \\
\hline Less patient compliance & Improves patient compliance \\
\hline $\begin{array}{l}\text { Not suitable for delivery of drugs with narrow absorption } \\
\text { window in small intestine region }\end{array}$ & $\begin{array}{l}\text { Suitable for delivery of drugs with narrow absorption window } \\
\text { in small intestine region }\end{array}$ \\
\hline $\begin{array}{l}\text { Not much advantageous for } \\
\text {-Drugs having rapid absorption through GIT }\end{array}$ & $\begin{array}{l}\text { Very much advantageous for } \\
\text {-Drugs which degrade in the colon } \\
\text {-Drugs acting locally in the stomach } \\
\text {-Drugs which are poorly at an alkaline pH }\end{array}$ \\
\hline No risk of dose dumping & $\begin{array}{l}\text {-Drugs which degrade in the colon } \\
\text {-Drugs having rapid absorption through GIT }\end{array}$ \\
\hline
\end{tabular}

\section{DIFFERENT APPOACHES FOR GRRDS: ${ }^{4}$}

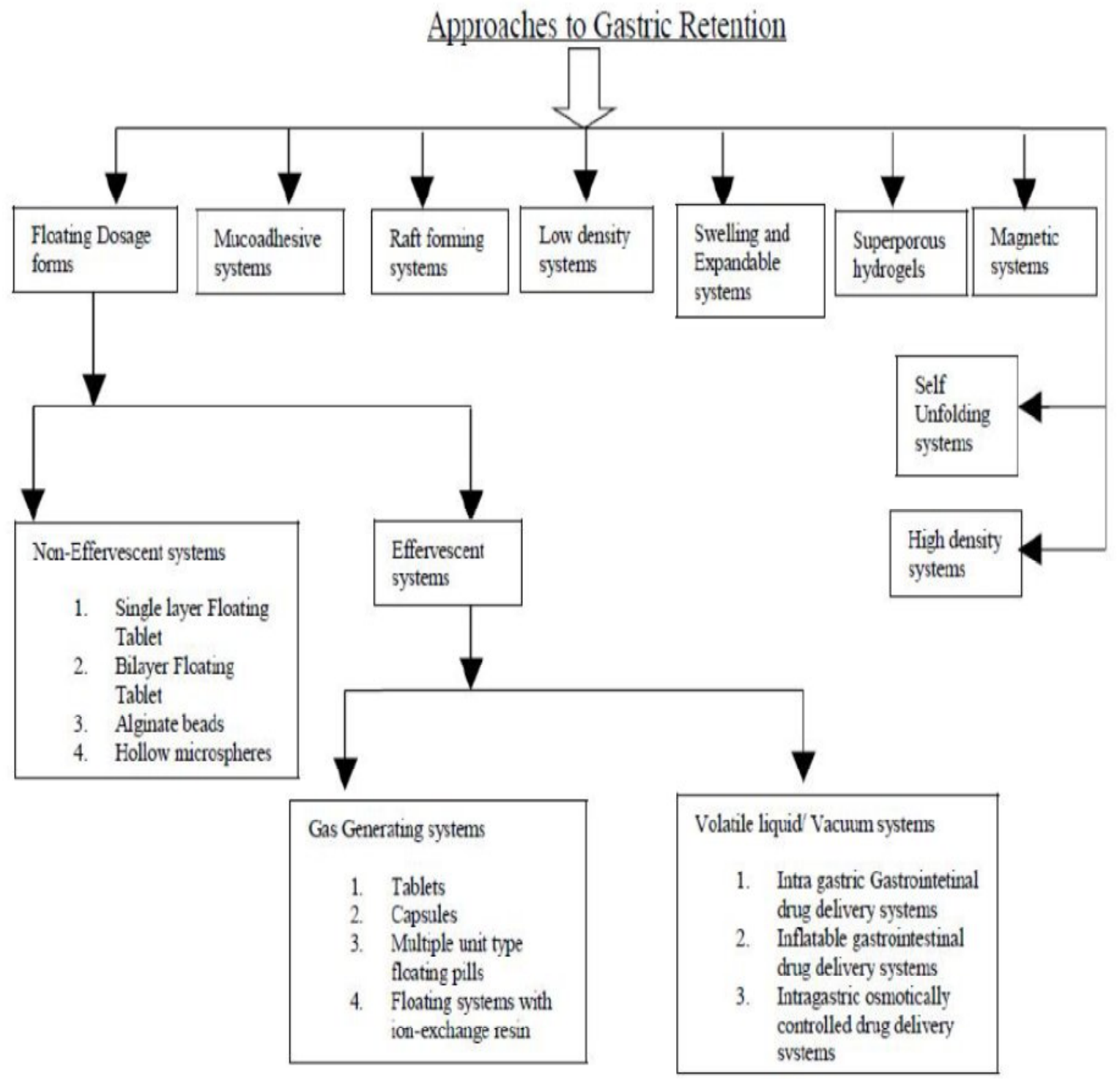

\section{OVERVIEW ON GENERAL APPROACHES TO GASTRIC RETENTION}

Various approaches for gastro retentive drug delivery systems are:

\section{A) Floating drug delivery ${ }^{2}$}

Floating Drug Delivery Systems (FDDS) have a bulk density lower than gastric fluids and thus remain buoyant in the stomach, (Fig.1), for a prolonged period of time, without affecting the gastric emptying rate and the drug is released slowly at a desired rate from the system, results in an increase in the gastric residence time and a better control of fluctuations in the plasma drug concentrations and after complete release of the drug, the residual system is emptied from the stomach. 


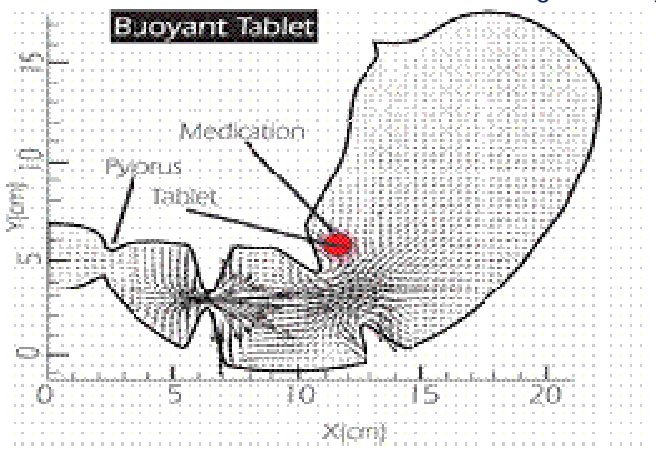

Figure1: Graphic of the buoyant tablet which is less dense than the stomach fluid and therefore remains in the fundus ${ }^{5}$

\section{B) Bio/Muco-adhesive systems ${ }^{2,7}$}

Bio/muco-adhesive systems bind to the gastric epithelial cell surface or mucin, which extends the GRT of drug delivery system in the stomach. The surface epithelial adhesive properties of mucin have been well recognized and applied to the development of GRDDS based on bio/muco-adhesive polymers. The ability to provide adhesion of a drug delivery system to the gastrointestinal wall provides longer residence time in a particular organ site, thereby producing an improved effect in terms of local action or systemic effect. Binding of polymers to the mucin/epithelial surface can be divided into three categories:

\section{a. Hydration-mediated adhesion:}

Certain hydrophilic polymers tend to imbibe large amount of water and become sticky, thereby acquiring bioadhesive properties.

\section{b. Bonding-mediated adhesion:}

The adhesion of polymers to a mucus/epithelial cell surface involves various bonding mechanisms, including physical-mechanical bonding and chemical bonding. Physical-mechanical bonds can result from the insertion of the adhesive material into the folds or crevices of the mucosa. Chemical bonds may be either covalent (primary) or ionic (secondary) in nature. Secondary chemical bonds consist of dispersive interactions (i.e., Vander Waals interactions) and stronger specific interactions such as hydrogen bonds. The hydrophilic functional groups responsible for forming hydrogen bonds are the hydroxyl and carboxylic groups.

\section{c. Receptor-mediated adhesion:}

Certain polymers bind to specific receptor sites on the cell surfaces, thereby enhancing the gastric retention of dosage forms. Various investigators have proposed different mucin-polymer interactions, such as:

- Wetting and swelling of the polymer to permit intimate contact with the biological tissue.

- Interpenetration of bioadhesive polymer chains and entanglement of polymer and mucin chains.

- $\quad$ Formation of weak chemical bonds.

- Sufficient polymer mobility to allow spreading.
Water transport followed by mucosal dehydration

The bioadhesive coated system when comes in contact with the mucus layer, various non-specific (Vander Waals, hydrogen bonding and/or hydrophobic interactions) or specific interactions occurs between the complimentary structures and these interactions last only until the turnover process of mucin and the drug delivery system should release its drug contents during this limited adhesion time, in order for a bioadhesive system to be successful.

\section{C) Low density systems ${ }^{1,2}$}

Low density systems $\left(<1 \mathrm{~g} / \mathrm{cm}^{3}\right)$ which have immediate buoyancy have been developed because, the gas-generating systems have a lag time before floating on the stomach contents, during which the dosage form may undergo premature evacuation through the pyloric sphincter. These are made of low density materials, entrapping air or oil. Most of the low density systems are multiple unit systems, also called as "microballoons" because of the low-density core. The preparation of these hollow microspheres (Fig.2), involves simple solvent evaporation or solvent diffusion methods. Polycarbonate, cellulose acetate, Eudragit S, calcium alginate, low methoxylated pectin and agar are commonly used as polymers. Drug release and buoyancy are dependent on the plasticizer-polymer ratio, quantity of polymer, and the solvent used.

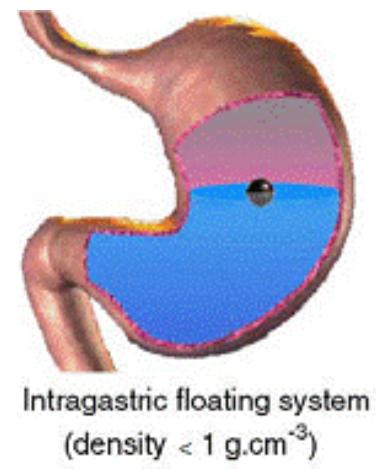

Figure 2: intragastric floating system ${ }^{1}$

\section{D) Superporous Hydrogels ${ }^{5,7}$}

Conventional hydrogels, with pore size ranging between $10 \mathrm{~nm}$ and $10 \mu \mathrm{m}$ has very slow process of water absorption and require several hours to reach an equilibrium state during which premature evacuation of the dosage form may occur while the superporous hydrogel (Fig.3), having average pore size $(>100 \mu \mathrm{m})$, swell to equilibrium size within a minute, due to rapid water uptake by capillary wetting through numerous interconnected open pores. Moreover they swell to a large size (swelling ratio 100 or more) and are intended to have sufficient mechanical strength to withstand pressure by gastric contractions. This is achieved by a co-formulation of a hydrophilic particulate material, Ac-Di-Sol (crosscarmellose sodium) 

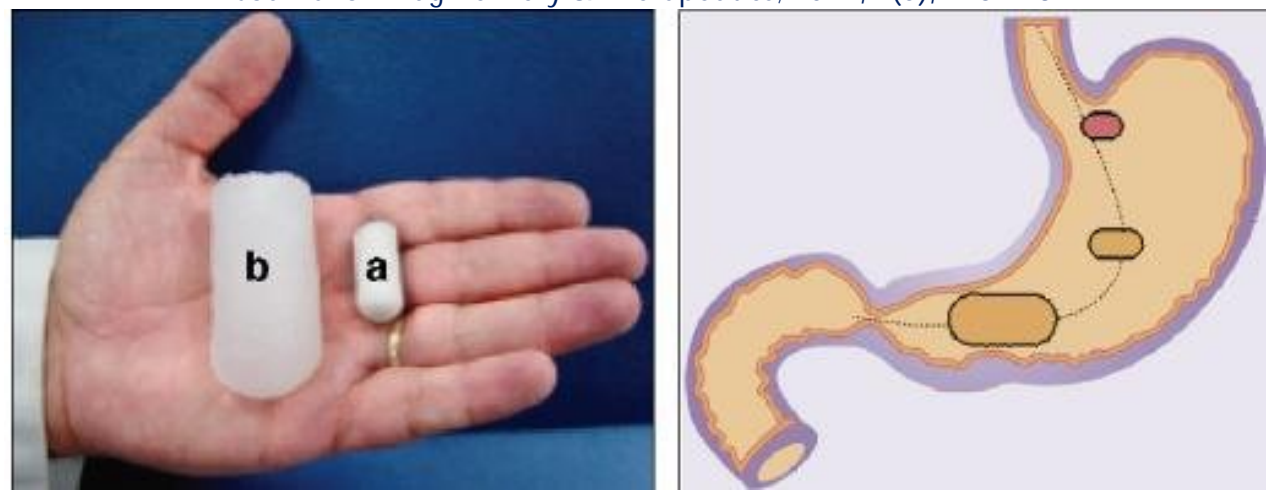

Figure 3: On the left, Superporous Hydrogels in its dry (a) and water-swollen (b) state. On the right, schematic illustration of the transit of Superporous Hydrogel. ${ }^{16}$

\section{E) High density systems ${ }^{1,2}$}

These systems with a density of about $3 \mathrm{~g} / \mathrm{cm}^{3}$ are retained in the rugae of the stomach and are capable of withstanding its peristaltic movements. A density of 2.6$2.8 \mathrm{~g} / \mathrm{cm}^{3}$ acts as a threshold value after which such systems can be retained in the lower part of the stomach. High density formulations include coated pellets. Coating is done by heavy inert material such as barium sulphate, zinc oxide, titanium dioxide, iron powder etc. They are retained in the antrum of stomach.

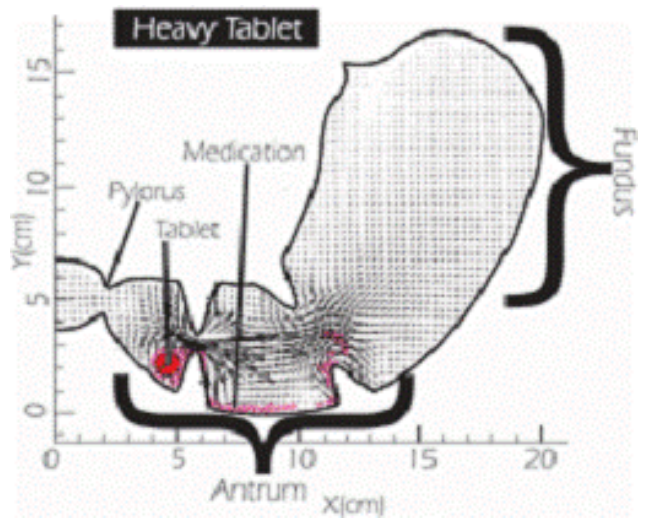

Figure 4: High density GRDDS $^{16}$

\section{RAFT FORMING SYSTEMS}

Raft forming systems have received much attention for the delivery of antacids and drug delivery for gastrointestinal infections and disorders. A simple meaning of Raft is a flat structure, typically made of planks, logs, or barrels, that floats on water and is used for transport or as a platform for swimmers. ${ }^{8}$ Here also we are considering something that floats on gastric content of stomach. The mechanism involved in the raft formation includes the formation of viscous cohesive gel in contact with gastric fluids, wherein each portion of the liquid swells forming a continuous layer called a raft. This raft floats on gastric fluids because of low bulk density created by the formation of $\mathrm{CO}_{2}$. Usually, the system contains a gel forming agent and alkaline bicarbonates or carbonates responsible for the formation of $\mathrm{CO}_{2}$ to make the system less dense and float on the gastric fluids. The system contains a gel forming agent (e.g. alginic acid), sodium bicarbonate and acid neutralizer, which forms a foaming sodium alginate gel (raft) when in contact with gastric fluids. The raft thus formed floats on the gastric fluids and prevents the reflux of the gastric contents (i.e. gastric acid) into the esophagus by acting as a barrier between the stomach and esophagus. A patent assigned to Reckitt and Colman Products Ltd., describes a raft forming formulation for the treatment of helicobacter pylori (H. Pylori) infections in the GIT. The composition contained drug, alginic acid, sodium bicarbonate, calcium carbonate, mannitol and a sweetener. These ingredients were granulated, and citric acid was added to the granules. The formulation produces effervescence and aerates the raft formed, making it float. $^{1,9}$

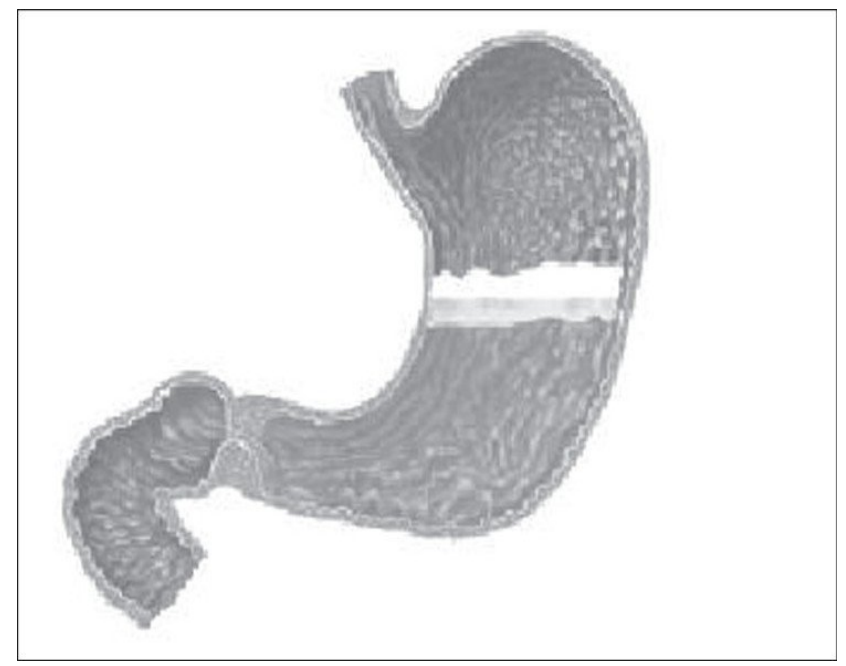

Figure 5: Schematic representation of raft forming system ${ }^{9}$

\section{ADVANCES IN RAFT FORMING APPROCH}

Alginates are established among the most versatile biopolymers, used in a wide range of applications. ${ }^{12}$ The conventional use of alginate as an excipient in drug products generally depends on the thickening, gel-forming, and stabilizing properties. Alginate-based raft-forming formulations have been marketed word-wide for over 30 years under various brand names, including Gaviscon. ${ }^{13}$ They are used for the symptomatic treatment of heartburn and oesophagitis, and appear to act by a unique mechanism which differs from that of traditional antacids. In the presence of gastric acid, alginates precipitate, forming a gel. Alginate-based raft-forming formulations usually contain sodium or potassium bicarbonate; in the presence of gastric acid, the bicarbonate is converted to carbon 


\section{Bhavsar et al}

Journal of Drug Delivery \& Therapeutics; 2012, 2(5), 123-128

dioxide which becomes entrapped within the gel precipitate, converting it into foam which floats on the surface of the gastric contents, much like a raft on water. Both in vitro and in vivo studies have demonstrated that alginate-based rafts can entrap carbon dioxide, as well as antacid components contained in some formulations, thus providing a relatively $\mathrm{pH}$-neutral barrier. Several studies have demonstrated that the alginate raft can preferentially move into the oesophagus in place, or ahead, of acidic 1) gastric contents during episodes of gastro-oesophageal reflux; some studies further suggest that the raft can act as a physical barrier to reduce reflux episodes. Although some alginate-based formulations also contain antacid2) components which can provide significant acid neutralization capacity, the efficacy of these formulations 3 ) to reduce heartburn symptoms does not appear to be totally dependent on the neutralization of bulk gastric contents.4) The strength of the alginate raft is dependent on several5) factors, including the amount of carbon dioxide generated and entrapped in the raft, the molecular properties of the alginate, and the presence of aluminium or calcium in the antacid components of the formulation. Raft formation occurs rapidly, often within a few seconds of dosing; hence alginate-containing antacids are comparable to traditional antacids for speed of onset of relief. Since the raft can be retained in the stomach for several hours, alginate-based raft-forming formulations can additionally provide longer-lasting relief than that of traditional antacids. Indeed, clinical studies have shown Gaviscon is superior to placebo, and equal to or significantly better than traditional antacids for relieving heartburn symptoms. Alginate-based, raft-forming formulations have been used to treat reflux symptoms in infants $\&$ children and in the management of heartburn and reflux during pregnancy. While Gaviscon is effective when used alone, it is compatible with, and does not interfere with the activity of antisecretory agents such as cimetidine. Even with the introduction of new antisecretory and promotility agents, alginate-rafting formulations will continue to have a role in the treatment of heartburn and reflux symptoms. Their unique non-systemic mechanism of action provides rapid and long-duration relief of heartburn and acid reflux symptoms.

\section{ADVANTAGE OF RAFT FORMING SYSTEM ${ }^{1,2,5,9}$}

They are used for the symptomatic treatment of heartburn and oesophagitis. It can be used in LPR. GERD, Laryngopharyngeal Reflux (LPR) refers to the backflow of stomach contents into the laryngeal and pharyngeal region. It does not interfere with the activity of promotility agent, antisecretory agents such as cimetidine.

Rapid and Long-duration of action can easily achieved by raft formation. It may show its action within seconds.

It will not interfere with function of pyloric sphincter.

Better patient compliance can be achieved and it is well tolerated.

\section{MARKETED PREPARATION: GAVISCON ${ }^{14}$}

Gaviscon Advance is an extra strength treatment for heartburn and indigestion including hiatus hernia and gastro oesophageal reflux disease also known as GERD. It does not cure the condition but rather is used to control the unpleasant symptoms and for me it works a treat. Gaviscon advance is a thick creamy suspension that is available in two flavours. Peppermint flavor and aniseed. It is quite pleasant to taste but a lot of people cannot bear the taste of aniseed.

\section{MECHANISM OF ACTION OF GAVISCON:}

The Gaviscon liquid is a thick suspension that on swallowing slides down the oesophagus into the stomach. It forms a barrier over the top of the stomach contents preventing the acid from rising into the oesophagus.
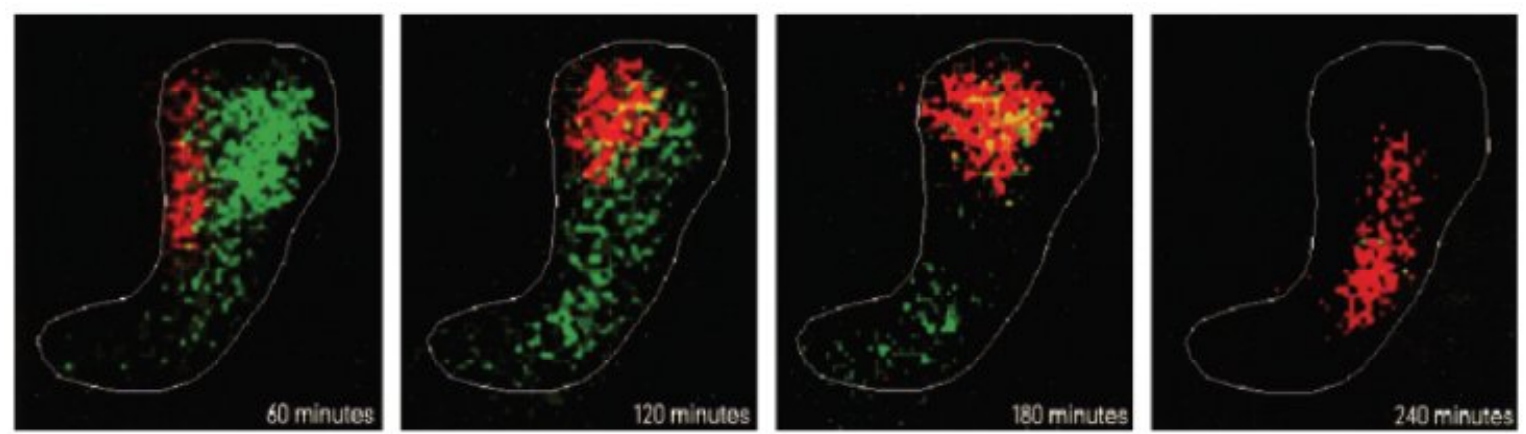

Figure 7: Scintigraph sequence showing Gaviscon Advance raft (red) above the meal (green) in the stomach. Times shown are post meal administration. This shows that GA remains in the stomach for 4 hours and until the meal has emptied ${ }^{11}$

\section{WHAT DOES IT CONTAIN PER 10ml DOSE?}

$1 \mathrm{~g}$ of Sodium Alginate. (Derived from seaweed).

$200 \mathrm{mg}$ of Potassium bicarbonate.

Calcium Carbonate.

Carbomer.

Methyl \& propyl hydroxybenzoates. (E218 \& E216).

Sodium Saccharin.

๑) 2011, JDDT. All Rights Reserved
However it has quite high sodium content so it will to reduce their sodium intake. It is sugar and gluten free. It is safe to use in pregnancy and during breast feeding. Some people may be allergic to some of the ingredients.

\section{CONCLUSION:}

Controlled release gastroretentive dosage forms (CRGRDF) enable prolonged and continuous input of the drug to the upper parts of the gastrointestinal (GI) tract and improve the bioavailability of medications that are characterized by a narrow absorption window. Based on the literature surveyed, it may be concluded that ISSN: 2250-1177 
Bhavsar et al

gastroretentive drug delivery offers various potential advantages for drug with poor bioavailability due their absorption is restricted to the upper gastrointestinal tract (GIT) and they can be delivered efficiently thereby maximizing their absorption and enhancing absolute bioavailability. And hence, it can be concluded that these dosage forms serve the best in the treatment of diseases related to the GIT, GERD and for extracting a prolonged action from a drug with a short half-life. Usually, the raft system contains a gel forming agent and alkaline bicarbonates or carbonates responsible for the formation of $\mathrm{CO}_{2}$ to make the system less dense and float on the gastric fluids. The system contains a gel forming agent (e.g. alginic acid), sodium bicarbonate and acid neutralizer, which forms a foaming sodium alginate gel (raft) when in

\section{REFERENCES:}

1. Nasa Praveen, Mahant Sheefali, Sharma Deepika, "Floating systems: A novel approach towards Gastroretentive drug delivery Systems", International Journal of Pharmacy and Pharmaceutical Sciences, 2010,2(3), 2-7

2. Debjit Bhowmik, Chiranjib.B, Margret Chandira, B. Jayakar, K.P.Sampath Kumar, "Floating Drug Delivery System-A Review", Der Pharmacia Lettre 2009, 1 (2) 199-218

3. Nayak Amit Kumar, Ruma Maji, Biswarup Das, "Gastroretentive drug delivery systems: a review", Asian Journal of Pharmaceutical and Clinical Research,2010,3(1), 2-10

4. Yadawad Mehaboob, K Kavitha, "Microbaloon as A Drug Delivery System: An Emerging Trend", International Journal of Research in Pharmaceutical and Biomedical Sciences, 2011, 2(1), 44-51

5. http://pharmastuff.blogspot.in/2011/06/over-view-of-gastroretentive-drug.html

6. Aleksandar Aleksovski, "Floating gastroretentive dosage forms - A novel approach for targeted and controlled drug delivery", Human,2012, 2(1), 23-30

7. Vinod K.R., Santhosh Vasa, Anbuazaghan S, David Banji1, Padmasri A, Sandhya S. Approaches for Gastroretentive Drug Delivery Systems; 2010, 1(2), 589-601.

8. http://www.thefreedictionary.com/raft
9. S.Punitha, G.sabitha, Kalal Vishal, S.Rajasekar, "Floating Drug delivery system- Chronotherapeutic Approach", International Research journal of Pharmacy,2011, 2(4), 38-45

10. Vyas S. P., Khar Roop K., Controlled Drug Delivery Concepts \& Advances, Vallabh Prakashan; $4^{\text {th }}$ edition;196217

11. Peter W. Dettmar, Julian A.McGlashan, Lesley M. Johnstone, John Sykes, and Phillip J. Berry, "The Role of Liquid Alginate Suspension (Gaviscon Advance ${ }^{\circledR}$ ) in the Management of Laryngopharyngeal Reflux (LPR)", G-NHSUK-51-07

12. http://informahealthcare.com/doi/abs/10.1081/DDC120003853

13. Mandel KG, Daggy BP, Brodie DA, Jacoby HI, "Review article: Alginate-raft formulations in the treatment of heartburn and acid reflux", SmithKline Beecham Consumer Health Care, Parsippany, NJ 07054, USA

14. http://www.gaviscon.co.uk/

15. D. E. Chickering, J. S. Jacob and E. Mathowitz, "Bioadhesive microspheres II: Characterisation and evaluation of bioadhesion involving hard, bioerodible polymers and soft tissue", Reactive Polymers, 1995, 25(1), 189-206

16. http://pharmastuff.blogspot.in/2011/06/over-view-of-gastroretentive-drug.html 